\title{
Factors influencing the relation of infant feeding to asthma and recurrent wheeze in childhood
}

\author{
A L Wright, C J Holberg, L M Taussig, F D Martinez
}

\begin{abstract}
Background-The relationship between infant feeding and childhood asthma is controversial. This study tested the hypothesis that the relation between breast feeding and childhood asthma is altered by the presence of maternal asthma. Methods-Healthy non-selected newborn infants $(n=1246)$ were enrolled at birth. Asthma was defined as a physician diagnosis of asthma plus asthma symptoms reported on $\geqslant 2$ questionnaires at $6,9,11$ or 13 years. Recurrent wheeze ( $\geqslant 4$ episodes in the past year) was reported by questionnaire at seven ages in the first 13 years of life. Duration of exclusive breast feeding was based on prospective physician reports or parental questionnaires completed at 18 months. Atopy was assessed by skin test responses at the age of 6 years.

Results-The relationship between breast feeding, asthma, and wheeze differed with the presence or absence of maternal asthma and atopy in the child. After adjusting for confounders, children with asthmatic mothers were significantly more likely to have asthma if they had been exclusively breast fed (OR 8.7, 95\% CI 3.4 to 22.2). This relationship was only evident for atopic children and persisted after adjusting for confounders. In contrast, the relation between recurrent wheeze and breast feeding was age dependent. In the first 2 years of life exclusive breast feeding was associated with significantly lower rates of recurrent wheeze (OR $0.45,95 \%$ CI 0.2 to 0.9 ), regardless of the presence or absence of maternal asthma or atopy in the child. Beginning at the age of 6 years, exclusive breast feeding was unrelated to prevalence of recurrent wheeze, except for children with asthmatic mothers in whom it was associated with a higher odds ratio for wheeze (OR 5.7, 95\% CI 2.3 to 14.1), especially if the child was atopic.
\end{abstract}

Conclusion-The relationship between breast feeding and asthma or recurrent wheeze varies with the age of the child and the presence or absence of maternal asthma and atopy in the child. While associated with protection against recurrent wheeze early in life, breast feeding is associated with an increased risk of asthma and recurrent wheeze beginning at the age of 6 years, but only for atopic children with asthmatic mothers.

(Thorax 2001;56:192-197)

Keywords: asthma; breast feeding; wheezing; infant feeding; atopy; allergic disease
The literature regarding the relation between infant feeding practices and the development of childhood asthma and allergic wheezing is conflicting. Although some larger studies ${ }^{1-3}$ have shown no significant relation between feeding history and asthma, others ${ }^{4}$ have found a protective effect of breast feeding for asthma in 6 year old children. Further confusing the picture is the fact that childhood wheezing encompasses both transient infectious wheeze, which predominates early in life, and allergic wheezing. While the risk factors, underlying mechanisms, and sequelae of these two types of wheezing may differ, ${ }^{5}$ both may be labelled "asthma" early in life.

The association between infant feeding and asthma is often assessed after adjusting for parental history of allergy to control for confounders and to determine whether allergic predisposition might alter the relationship. However, given the well documented individual variability in milk composition, ${ }^{6}$ it is plausible that the milk of asthmatic mothers may differ from that of non-asthmatic mothers resulting in differential effects of breast feeding on asthma depending on the presence or absence of maternal asthma. This paper assesses the relationship between breast feeding and the development of childhood asthma and wheeze after adjustment for maternal asthma.

\section{Methods}

Data for this report came from the Tucson Children's Respiratory Study (CRS), a prospective longitudinal study of the risk factors for the development of asthma in childhood. Healthy newborn infants $(n=1246)$ and their families using the largest local health maintenance organisation (HMO) were enrolled at birth between 1980 and 1984; more detailed descriptions are available elsewhere. ${ }^{78}$ Infants were not selected with reference to allergic history or feeding plans. Information on parental characteristics (ethnicity, education, and physician diagnosed asthma) and number of siblings in the household was obtained by questionnaire at enrollment. Data on day care attendance in the first 6 months of life was obtained by questionnaire at year 6 .

Infant feeding information was derived from two sources; concordance between the two sources was very high (>90\%). ${ }^{9}$ Briefly, at each health surveillance visit the HMO physicians recorded on a standardised form whether the child was currently breast fed and/or receiving formula foods or milk. Information was also obtained by questionnaire at year 2 about the age at which formula and solids were introduced. Prospective data (from health surveil- 
Table 1 Characteristics of children by infant feeding history

\begin{tabular}{|c|c|c|c|}
\hline & $\begin{array}{l}\text { Never BF } \\
(n=170)\end{array}$ & $\begin{array}{l}\text { Exclusive BF <4 } \\
\text { months }(n=514)\end{array}$ & $\begin{array}{l}\text { Exclusive } B F \geqslant 4 \\
\text { months }(n=359)\end{array}$ \\
\hline$\% \geqslant 1$ non-Hispanic parent ${ }^{\star}$ & 69.4 & 82.7 & 92.2 \\
\hline$\% \geqslant 16$ years maternal schooling ${ }^{\star}$ & 5.3 & 18.7 & 24.2 \\
\hline$\%$ mother smoked in child's infancy ${ }^{\star}$ & 29.8 & 28.0 & 16.7 \\
\hline \multicolumn{4}{|l|}{$\%$ with $\geqslant 2$ siblings or attending day care with } \\
\hline$\geqslant 6$ other children & 36.6 & 28.2 & 26.5 \\
\hline$\%$ ever maternal MD asthma & 7.2 & 11.4 & 11.6 \\
\hline$\%$ of mothers with current asthma symptoms & 2.4 & 4.8 & 5.7 \\
\hline$\%$ paternal MD asthma & 16.6 & 12.1 & 11.4 \\
\hline
\end{tabular}

$\mathrm{BF}=$ breast feeding; $\mathrm{MD}$ asthma $=$ physician diagnosed asthma.

${ }^{\star} \mathrm{p}<0.0001$ for relation with feeding history.

lance visits) were given priority and used to classify $74 \%$ of the subjects. Children were categorised with regard to duration of exclusive breast feeding (never breast fed, breast fed exclusively $<4$ months, breast fed exclusively $\geqslant 4$ months). Data on maternal smoking during the infant's first year of life was also obtained in the year 2 questionnaire.

Questionnaires ascertaining respiratory health were completed at 2, 3, 6, 9, 11 and 13 years (mean (SD) age: $1.6(0.4), 2.9(0.5), 6.3$ (1.0); 8.6 (0.7); 10.9 (0.6), and $13.5(0.6)$ years, respectively). At each age the parents were asked whether the child ever had asthma, whether a doctor said the child had asthma, whether the child had asthma symptoms in the past year, and how frequently the child wheezed in the past year. Recurrent wheeze was defined at each age as wheezing $\geqslant 4$ times in the past year. At years 2 and 3 parents were asked whether their child had wheezed during the past year and, if so, how often on a 5 point scale from "very rarely" to "on most days". Children scoring $>2$ on this scale were defined as having recurrent wheeze in the past year. Asthma was defined as physician diagnosed asthma in the child and wheeze or asthma symptoms reported on two or more questionnaires from age 6 to 13 years. Only these questionnaires were considered in the definition of asthma to minimise the possibility that early infectious wheeze was misdiagnosed as asthma. At age 6 skin prick tests were conducted using seven locally significant allergens, as described elsewhere. ${ }^{10}$

Relationships between feeding history and asthma in the child were first assessed bivariately and then stratified according to the presence or absence of maternal asthma. Standard statistical procedures ( $t$ tests and contingency tables using the $\chi^{2}$ distribution) were used to assess statistical significance. Logistic regression was used to assess whether the odds of asthma or, separately, recurrent wheeze were

Table 2 Percentage ( $n$ ) with asthma by infant feeding category and parental asthma status

\begin{tabular}{lllll}
\hline & Total & Never BF & $\begin{array}{l}\text { Exclusive BF } \\
<4 \text { months }\end{array}$ & $\begin{array}{l}\text { Exclusive BF } \\
\geqslant 4 \text { months }\end{array}$ \\
\hline Total group & $14.4 \%(133 / 926)$ & $12.2 \%(18 / 147)$ & $13.5 \%(60 / 445)$ & $16.5 \%(55 / 334)$ \\
Maternal asthma & $30.3 \%(30 / 99)$ & $9.1 \%(1 / 11)$ & $23.5 \%(12 / 51)$ & $45.9 \%(17 / 37)$ \\
No maternal asthma & $12.4 \%(101 / 816)$ & $11.4 \%(15 / 132)$ & $12.3 \%(48 / 390)$ & $12.9 \%(38 / 294)$ \\
Paternal asthma & $22.3 \%(25 / 112)$ & $26.1 \%(6 / 23)$ & $16.0 \%(8 / 50)$ & $28.2 \%(11 / 39)$ \\
No paternal asthma & $13.0 \%(99 / 761)$ & $9.7 \%(11 / 113)$ & $12.3 \%(45 / 367)$ & $15.3 \%(43 / 281)$ \\
\hline $\mathrm{BF}=$ breast feeding. & & & & \\
${ }^{\star} \chi^{2}=7.74 ; \mathrm{p}<0.05$, trend $\chi^{2} \mathrm{p}<0.005$. & & &
\end{tabular}

related to breast feeding and maternal asthma after adjusting for maternal education $(\geqslant 16 v$ $<16$ years of schooling), maternal smoking in the first year of life, sex, ethnicity (one or more white non-Hispanic parent $v$ all others), presence of two or more siblings at home or use of day care with six or more other children $v$ neither exposure in the first 6 months of life, and paternal asthma. Log-linear modelling using saturated models was used to compute partial $\chi^{2}$ statistics to determine statistical significance of effects at an $\alpha$ level of 0.05 . The partial $\chi^{2}$ is the difference between the goodness of fit statistic (likelihood ratio $\chi^{2}$ ) with and without the term or effect being tested, and can be used to test the hypothesis that the effect is zero. ${ }^{11}$

All components of the study were approved by the University of Arizona institutional review board and informed consent was obtained from the parents.

\section{Results}

POPULATION CHARACTERISTICS

Data regarding breast feeding were available for 1043 children. The majority of children $(83.7 \%)$ were breast fed, although most breast fed infants $(58.8 \%)$ were given formula or other foods in the first 3 months of life. Mothers were significantly more likely to breast feed exclusively for $\geqslant 4$ months if they had completed college, were non-Hispanic, or did not smoke in the child's first year of life, as shown in table 1 . Infant feeding was unrelated to the presence of maternal asthma or whether the mother had current symptoms (assessed soon after delivery), the child's sex, day care use or the presence of other siblings in the first 6 months, or paternal history of physician diagnosed asthma.

By the age of 13 years $14.3 \%$ of children had asthma. The proportion of children with recurrent wheeze was relatively constant, ranging from $7.5 \%$ in the first 18 months to $8.7 \%$ at age $13 ; 73 \%$ of children with asthma reported recurrent wheeze between the ages of 6 and 13 .

INFANT FEEDING AND MATERNAL ASTHMA AS PREDICTORS OF CHILDHOOD ASTHMA

There was no significant relationship between asthma by age 13 and duration of exclusive breast feeding (table 2). However, the association between feeding and asthma differed according to the presence or absence of maternal asthma. In children with non-asthmatic mothers the percentage with asthma by age 13 was unrelated to duration of breast feeding, but in children with a maternal history of asthma there was a direct relation between duration of breast feeding and asthma. Current asthma symptoms in the mother did not appear to confound the relationship (data not shown); $85 \%$ of asthmatic mothers were atopic. The presence of asthma in the father did not affect the relation between breast feeding and asthma (table 2).

Logistic regression was used to assess the relation between childhood asthma and feeding history and maternal asthma, after adjusting for confounders. The odds ratios (OR) for 
Table 3 Percentage ( $n$ ) with recurrent wheeze, by infant feeding category and maternal asthma status, in the first 3 years of life and at 6-13 years of age

\begin{tabular}{|c|c|c|c|c|}
\hline & Total & Never $B F$ & $\begin{array}{l}\text { Exclusive BF } \\
<4 \text { months }\end{array}$ & $\begin{array}{l}\text { Exclusive BF } \\
\geqslant 4 \text { months }\end{array}$ \\
\hline \multicolumn{5}{|l|}{ Age $\leqslant 3$ years } \\
\hline Maternal asthma & $18.4 \%(18 / 98)$ & $27.3 \%(3 / 11)$ & $19.2 \%(10 / 52)$ & $14.3 \%(5 / 37)$ \\
\hline No maternal asthma* & $11.2 \%(89 / 795)$ & $14.4 \%(19 / 132)$ & $12.5 \%(48 / 384)$ & $7.9 \%(22 / 279)$ \\
\hline \multicolumn{5}{|l|}{ Age $6-13$ years } \\
\hline Maternal asthma & $34.0 \%(36 / 106)$ & $25.0 \%(3 / 12)$ & $29.8 \%(17 / 57)$ & $42.2 \%(16 / 37)$ \\
\hline No maternal asthma & $15.5 \%(131 / 847)$ & $20.1 \%(28 / 139)$ & $13.7 \%(56 / 408)$ & $15.7 \%(47 / 300)$ \\
\hline
\end{tabular}

developing asthma at the age of 6-13 years were calculated relative to children not exclusively breast fed for $\geqslant 4$ months with nonasthmatic mothers for three groups: (1) children exclusively breast fed for $\geqslant 4$ months with asthmatic mothers; (2) children exclusively breast fed for $\geqslant 4$ months with nonasthmatic mothers; and (3) children not exclusively breast fed for $\geqslant 4$ months with asthmatic mothers. Exclusive breast feeding for $\geqslant 4$ months in the presence of maternal asthma was associated with a significantly increased odds ratio for developing asthma in the child (OR 8.7, 95\% CI 3.4 to 22.2) after adjusting for confounders; the results were unchanged when maternal asthma was limited to those with current symptoms. Maternal asthma in the absence of exclusive breast feeding was associated with increased odds of asthma of borderline significance (OR 2.1, 95\% CI 0.9 to 5.1 ). Other factors associated with an increased risk for asthma were atopy (OR 4.1, 95\% CI 2.5 to 6.8), male sex (OR 1.6, 95\% CI 1.0 to 2.7 ), and paternal asthma (OR 2.0, 95\% CI 1.0 to 3.7). As we have shown elsewhere, ${ }^{12}$ early exposure to children either at home or in large group day care was associated with significantly reduced rates of asthma (OR $0.42,95 \%$ CI 0.2 to 0.8 ).

\section{RECURRENT WHEEZE AND INFANT FEEDING HISTORY}

The relation of recurrent wheeze to breast feeding varied with age. Through 36 months exclusive breast feeding for $\geqslant 4$ months was associated with significantly lower rates of recurrent wheeze $(8.9 \% v 13.8 \%, \mathrm{p}<0.05)$. After that age exclusive breast feeding showed no relation to recurrent wheeze $(17.1 \%$ v $18.5 \%, \mathrm{p}<0.59)$. However, stratification by maternal asthma status indicated that the protective effect of exclusive breast feeding up to and including the age of 3 years existed for both those with and without maternal asthma (table 3). Beyond that age recurrent wheeze tended to increase if the child was exclusively breast fed, but only if the mother had asthma.

EFFECT OF ATOPY IN THE CHILD

Since we had previously shown that atopic status of the child altered the relation between breast feeding and recurrent wheeze, ${ }^{9}$ effect modification by atopy was assessed. As shown in fig 1 , the relation between asthma and breast feeding in children of asthmatic mothers existed only for children who were themselves atopic. The relative risk of asthma associated with exclusive breast feeding was of similar

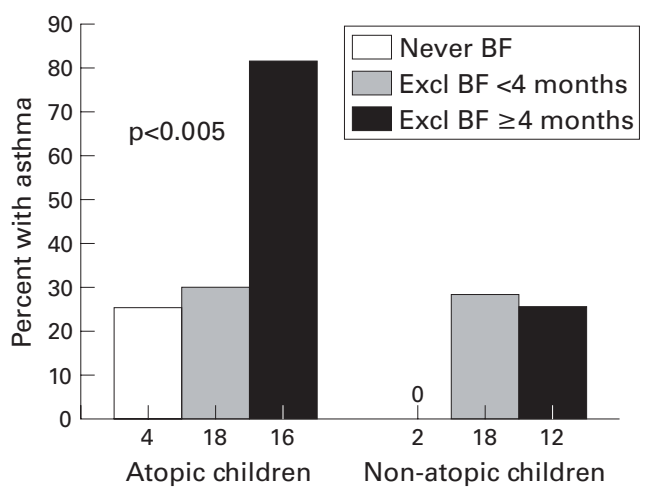

Figure 1 Percentage of children with asthma at 6-13 years for those with maternal asthma, by infant feeding category and atopy in the child. BF=breast feeding.

magnitude at each survey between the ages of 6-13 for atopic children with maternal asthma (fig 2A). There was no risk associated with exclusive breast feeding for non-atopic children with maternal asthma or for children who had non-asthmatic mothers. Atopy in the child was unrelated to the method of infant feeding $(p<0.78)$, even after stratifying by the presence or absence of maternal asthma (data not shown).

To assess further the significance of the interactions, a log-linear model was constructed including four variables: asthma and atopy in the child, exclusive breast feeding for $\geqslant 4$ months, and maternal asthma status. The four-way interaction between these variables was of borderline significance $(p<0.08)$. The interaction term including asthma, maternal asthma, and breast feeding was significant $(p<0.02)$, indicating that the interaction between maternal asthma and breast feeding remained significantly related to asthma in the child after taking the other interactions into account.

Since atopy in the child altered the relation between breast feeding and asthma, the relation of atopy to recurrent wheeze was assessed (table 4). In the first years of life recurrent wheeze was unrelated to atopy. However, beginning at the age of 6 , recurrent wheeze was significantly more common in atopic children. Figure 2B shows the relative risk for recurrent wheeze associated with exclusive breast feeding by maternal asthma status and atopy in the child. In the first three years of life breast feeding tended to be associated with lower rates of recurrent wheeze, and the relationship was unaltered by either atopy or maternal asthma status. Beginning at age 6, however, recurrent wheeze was increased among exclusively breast fed children, but only if they had asthmatic mothers and were themselves atopic. In the other groups, breast feeding showed no relation with recurrent wheeze.

Logistic regression was used to assess relationships with recurrent wheeze after adjusting for confounders. Interaction terms were not used in the first three years of life since neither maternal asthma nor atopy modified the relation between breast feeding and recurrent wheeze at this age. After adjusting for confounders, exclusive breast feeding was associ- 
Table 4 Percentage $(n)^{+}$with recurrent wheeze, by child's atopic status at age 6

\begin{tabular}{llrll}
\hline & Total & Atopic & Non-atopic & p value* \\
\hline 0-18 months & $7.5 \%(79 / 1054)$ & $8.2 \%(23 / 280)$ & $7.2 \%(31 / 431)$ & NS \\
8-36 months & $5.9 \%(55 / 937)$ & $8.0 \%(21 / 262)$ & $6.3 \%(25 / 398)$ & NS \\
6 years & $7.7 \%(78 / 1016)$ & $13.0 \%(38 / 292)$ & $4.5 \%(20 / 442)$ & $\mathrm{p}<0.00005$ \\
8 years & $7.2 \%(60 / 832)$ & $15.0 \%(37 / 246)$ & $4.2 \%(15 / 360)$ & $\mathrm{p}<0.000001$ \\
11 years & $9.7 \%(90 / 929)$ & $20.1 \%(55 / 274)$ & $3.9 \%(16 / 411)$ & $\mathrm{p}<0.000001$ \\
13 years & $8.7 \%(61 / 702)$ & $16.1 \%(35 / 218)$ & $4.0 \%(12 / 298)$ & $\mathrm{p}<0.000001$ \\
\hline
\end{tabular}

*Atopic $v$ non-atopic children.

$\dagger$ Fewer children were skin tested at age $6(n=737)$ than provided information on questionnaires.

ated with a significantly lower odds ratio of recurrent wheeze before the age of 2 (OR 0.45 , $95 \%$ CI 0.2 to 0.9 ); by the age of 3 the odds ratio was no longer significant. As expected, neither maternal asthma nor atopy in the child significantly affected the odds of recurrent wheeze in the early years of life. In contrast, exclusive breast feeding was associated with higher odds of recurrent wheeze at age 6-13 (OR 5.7, 95\% CI 2.3-14.1).

\section{Discussion}

This analysis sought to clarify the confusing picture relating infant feeding to childhood asthma and wheeze by showing that the presence of maternal asthma and atopy in the child alters the relationship. In the first years of life, longer exclusive breast feeding was associated with lower rates of recurrent wheeze, regardless of both maternal asthma status and
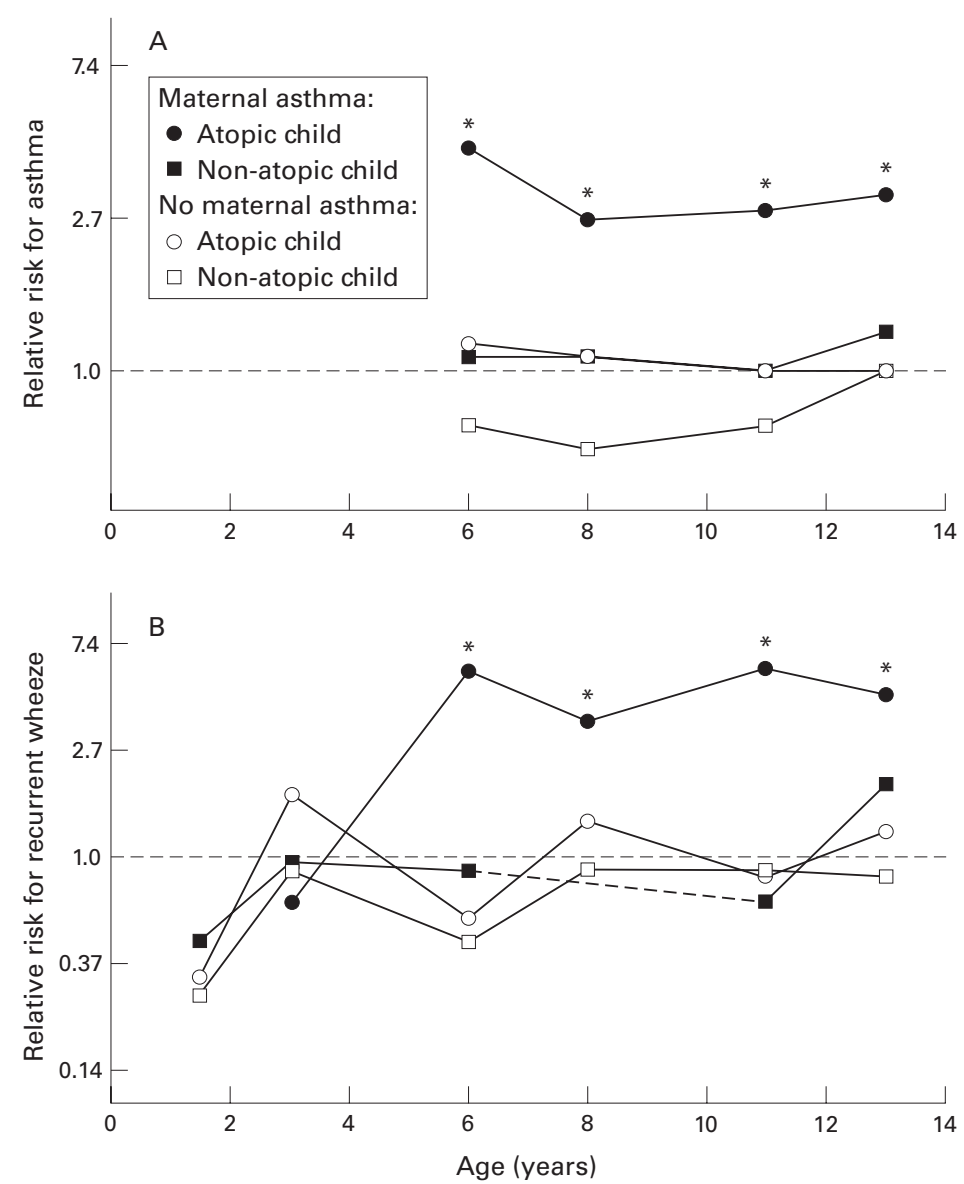

Figure 2 Relative risks for $(A)$ asthma and (B) recurrent wheeze associated with exclusive breast feeding for $\geqslant 4$ months compared with children breast fed for $<4$ months or never, by maternal asthma and atopy in the child. ${ }^{\star} p<0.00001$ for difference between exclusively breast fed atopic children with asthmatic mothers $v$ all other groups. atopy in the child. In contrast, longer exclusive breast feeding was associated with an increased risk of both asthma and recurrent wheeze at 6-13 years of age, but only in atopic children of asthmatic mothers. There was no relation between asthma and infant feeding in children with non-asthmatic mothers or in those who were themselves non-atopic.

Whether breast feeding protects against the development of asthma and/or recurrent wheeze has been long debated. ${ }^{13}$ While differences in methods and definitions may account for some of the conflicting findings, this analysis suggests that lack of stratification by maternal asthma and allergic predisposition in the child may have obscured how the relationship changes with the child's age and atopic status. Most studies reporting an apparent protective effect of breast feeding ${ }^{14}{ }^{15}$ assessed "asthma" in the first years of life. At this age, both the immunological components of milk, such as secretory IgA, which alter susceptibility to infection, ${ }^{16}$ and growth factors which facilitate maturation of organs, possibly including the lung, ${ }^{17}$ may account for the well documented protective effect of breast feeding against wheezing illnesses early in life. ${ }^{6}{ }^{18-20}$

A protective effect against later asthma is more controversial. Several large population based studies ${ }^{1-3}$ have found no relation between feeding history and asthma but the results were not adjusted by the presence of maternal asthma or atopy in the child. One recent study ${ }^{4}$ in a large sample found a protective effect of breast feeding against later asthma. However, the authors assessed the cumulative incidence of asthma to the age of 6 , thus including diagnoses based on the predominantly infectious wheeze that occurs before this age. We have shown a similar protective effect of breast feeding on recurrent wheeze in non-atopic children at the age of $6^{9}$; others have reported similar findings. ${ }^{21}$ The current study used a more stringent definition of asthma, and results were identical for recurrent wheeze independent of a diagnosis of asthma. Furthermore, while breast feeding was associated with lower rates of recurrent wheeze early in life, its direct association with later asthma in children of asthmatic mothers was seen only for allergic asthma as confirmed with objective markers of atopy. In addition, a dose response was observed with longer exclusive breast feeding carrying the greatest risk of asthma for children of asthmatic mothers.

If the association between breast feeding and asthma reported here is biologically based, it may be explained in two ways. Firstly, the milk of allergic mothers may differ from that of non-allergic mothers in ways that affect subsequent allergic susceptibility. Unlike T helper 1 (Th1) conditions which are associated with antimicrobial immunity, asthma is a Th2 disease, ${ }^{22}$ reflected in the preponderance of interleukin (IL)-4 and IL-5 which appear to direct the Th1/Th2 balance towards allergic hypersensitivity. If the cytokines present in milk ${ }^{23}$ differed by maternal atopic status, they might influence the polarisation of the infant's immune response. In vitro experiments by 
Allardyce and Wilson ${ }^{24}$ showed that cord blood lymphocytes stimulated with supernatants from milk of atopic mothers were significantly more likely to produce IgE than were lymphocytes stimulated with supernatants from non-atopic mothers. It is not known what components of milk are responsible for the observed effect; the levels of IgE in milk are negligible and there is only one unconfirmed report of the presence of IL- 4 and IL- 5 in human milk. ${ }^{25}$ Differences in the levels of long chain polyunsaturated fatty acid levels have also been found in the milk of atopic compared with non-atopic mothers ${ }^{26}$ although the significance of these substances for allergic asthma is unclear. One recent study found that milk contains large amounts of soluble CD14, ${ }^{27}$ a substance that is inversely associated with total serum IgE. ${ }^{28}$ If the levels of soluble CD14 vary in milk as they do in serum by atopic status, this variability might influence subsequent development of the immune system in the child. In addition, it could account for our recent observation that total serum IgE was raised in children of mothers with high $\mathrm{IgE}$ only if they had been breast fed, while the reverse was true for mothers with low IgE. ${ }^{29}$

An equally plausible speculation is that breast feeding alters some other outcome in the infant which, in turn, affects susceptibility to asthma, particularly among those who are genetically at risk. It has been hypothesised ${ }^{30}$ that one cause of the worldwide increase in asthma may be global changes in exposure to infectious organisms through improved sanitation and widespread use of antibiotics. In particular, it has been hypothesised ${ }^{24}$ that exposure early in life to bacteria and their products (largely through bacteria in the intestinal tract) fosters dendritic cell maturation and production of IL-12 which stimulates a Th1 response. The gut flora of infants in the industrialised world (where asthma prevalence is high) is less diverse and lower in Gram negative organisms than that currently found in infants in the developing world. ${ }^{31} 32$ Other studies have shown that evidence of past infection with orofaecal and foodborne (but not airborne) organisms was associated with a lower prevalence of asthma. ${ }^{33}$ With regard to infant feeding, exclusively breast fed infants have lower levels of Gram negative enterobacteria in their gastrointestinal tract ${ }^{34}$ and less diversity of colonising species. ${ }^{35}$ In addition, breast feeding protects against a wide range of infections. ${ }^{19}{ }^{36}$ Both of these effects provided critical selective advantage under the conditions in which the immune system of Homo sapiens evolved. However, these benefits of breast feeding may reduce the stimulus for maturation of dendritic cells in the context of reduced exposure to microbes, thereby attenuating or delaying the Th1 response, particularly in infants who are doubly susceptible - by virtue of both a parental history of asthma and their own atopy.

It is also possible that the relationship between breast feeding and asthma in children of asthmatic mothers results from reporting bias. Asthmatic mothers who breast feed may behave differently from asthmatic mothers who do not breast feed in ways which affect their child's risk of being diagnosed with asthma. For example, they may be more likely to seek medical attention for wheeze in their child or to remember a diagnosis of asthma. However, the consistency of findings for both recurrent wheeze and asthma by the age of 6 suggests that the association with breast feeding in children of asthmatic mothers is not due to differential recall of asthma diagnoses or to use of health services. Such mothers may also differ with regard to medication use during pregnancy which might affect the development of the immune system in some as yet undetermined way in the infant, although the lack of change when analyses were limited to mothers with current symptoms makes this explanation unlikely. It is also impossible to differentiate shared exposures between breast fed infants and their mothers from potential differences in milk. However, in Tucson, asthma occurs most commonly in children who are sensitised to ubiquitous moulds rather than to indoor or other localised allergens. ${ }^{37}$ Although the observed effects remained significant after adjusting for potential confounders, we cannot completely exclude the possibility that either unmeasured confounders or some reporting bias may account for the current findings.

It is important to put the finding of increased asthma among atopic children of asthmatic mothers into perspective. For the majority of children (89\%) who do not have a maternal history of asthma, exclusive breast feeding was associated with lower rates of recurrent wheeze in the first years of life and had no relation with recurrent wheeze thereafter. In children with maternal asthma exclusive breast feeding was associated with protection from recurrent wheeze in the first 3 years of life; after adjusting for confounders this effect was significant only to 2 years. For children with maternal asthma who were non-atopic ( $5 \%$ of the population) exclusive breast feeding was not associated with any increase after the age of 6 in either recurrent wheeze or asthma. It was only in atopic children with maternal asthma ( $6 \%$ of the population) that longer exclusive breast feeding was associated with significantly higher odds of both recurrent wheeze and asthma after the age of 6 . Even if the relationship between breast feeding and asthma in children of asthmatic mothers is substantiated by other studies, the effects would need to be weighed against the many other health benefits ${ }^{38}$ associated with breast feeding including optimal nutrition, protection against infection, potential cognitive advantages, and maternal health. Finally, since it is unknown whether a child will become atopic until well past the time that infant feeding choices are made, there is no need to reconsider current recommendations that infants be exclusively breast fed for 6 months.

The authors are indebted to the study nurses Marilyn Lindell and Lydia De La Ossa and to Debra Stern for technical assistance.

This study was funded through NHLBI grants HL14136 and RO1 HL56177. 
1 Wjst M, Dold S, Reitmeier P, et al. Does breast feeding prevent asthma and allergies? Results of the Munich asthma

2 Lewis S, Butland B, Strachan D, et al. Study of the aetiology of wheezing illnesses at age 16 in two national British birth cohorts. Thorax 1996;51:670-6.

3 Schwartz J, Gold D, Dockery DW, et al. Predictors of asthma and persistent wheeze in a national sample of children in the United States. Am Rev Respir Dis 1990;142: 555-62.

4 Oddy WH, Holt PG, Sly PD, et al. Association between breast feeding and asthma in 6 year old children: findings of a prospective birth cohort study. BMF 1999;319:815-9.

5 Martinez FD, Wright AL, Taussig LM, et al and The Group Health Medical Associates. Asthma and wheezing in the first six years of life. N Engl f Med 1995;332:133-8.

6 Downham MAPS, Scott R, Sims DG, et al. Breast-feeding protects against respiratory syncytial virus infections. $B M \mathcal{F}$ 1976;2:274-6.

7 Taussig LM, Wright AL, Harrison HR, et al. The Tucson Children's Respiratory Study (I): Design and implementation of a prospective study of acute and chronic respiratory illness in children. Am f Epidemiol 1989;129:1219-31.

8 Wright AL, Taussig LM, Ray CG, et al. The Tucson Children's Respiratory Study (II): Lower respiratory tract illness in the first year of life. Am f Epidemiol 1989;129: 1232-46.

9 Wright AL, Holberg CJ, Taussig LM, et al. Relationship of infant feeding to recurrent wheezing at age six. Arch Pediat Adolesc Med 1995;149:758-63.

10 Halonen M, Stern DA, Wright AL, et al. Alternaria as a major allergen for asthma in children raised in a desert environment. Am f Respir Crit Care Med 1997;155:135661.

11 Norusis MJ. SPSSX advanced statistics guide. New York: McGraw-Hill, 1985.

12 Ball TM, Castro-Rodriguez JA, Griffith KA, et al. Siblings, day care attendance and the risk of asthma and wheezing day care attendance and the risk of asthma and wh
during childhood. N Engl f Med 2000;343:538-43.

13 Kramer MS. Does breast feeding help protect against atopic disease? Biology, methodology and a golden jubilee of condisease? Biology, methodology and a
troversy. $\mathcal{F}$ Pediatr 1988;112:181-90.

14 Arita M, Mikawa H, Shirataka M, et al. Epidemiological research on incidence of atopic disease in infants and children in relation to their nutrition in infancy. Arerugi fapanese F Allergol 1997;46:354-69.

15 Hide DW, Guyer BM. Clinical manifestations of allergy related to breast and cow's milk feeding. Arch Dis Child 1981;56:172-5.

16 Hanson LA. Breastfeeding provides passive and likely longlasting active immunity. Ann Allergy Asthma Immuno 1998;81:523-33

17 Martinez FD, Morgan WJ, Wright AL, et al. Breastfeeding, lung function and LRIs during the first year of life. Am Rev Respir Dis 1988:137:405.

18 Wright AL, Holberg CJ, Martinez FD, et al. Breastfeeding and lower respiratory tract illness in the first year of life. and lower respiratory

19 Howie PW, Forsyth JS, Ogston SA, et al. Protective effect of breastfeeding against infection. BMF 1990;300:11-6.

20 Holberg CF, Wright AL, Martinez FD, et al. Risk factors for respiratory syncytial virus associated LRIs in the first year of life. Am f Epidemiol 1991;133:1135-51.
21 Burr ML, Limb ES, Maguire MJ, et al. Infant feeding, wheezing and allergy: a prospective study. Arch Dis Child 1993;68:724-8.

22 Holt PG, Sly PD, Bjorksten B. Atopic versus infectious diseases in childhood: a question of balance? Pediatr Allergy Immunol 1997;8:53-8.

23 Goldman AS, Chheda S, Garofalo R, et al. Cytokines in human milk. Properties and potential effects upon the mammary gland and neonate. 7 Mammary Gland Biol Neoplasia 1996;1:251-8.

24 Allardyce RA, Wilson A. Breast milk cell supernatants from atopic donors stimulate corb blood IgE secretion in vitro. Clin Allergy 1984;14:259-67.

25 Bottcher MF, Jenmalm MC, Garofalo RP, et al. Cytokines in breast milk from allergic and nonallergic mothers. Pediatr Res 2000;47:157-62.

26 Duchen K, Yu G, Bjorksten B. Atopic sensitization during the first year of life in relation to long chain polyunsaturated fatty acid levels in human milk. Pediatr Res 1998;44:478-84.

27 Labeta MO, Vidal K, Rey Nores JE, et al. Innate recognition of bacteria in human milk is mediated by a milk-derived highly expressed pattern recognition receptor, soluble highly expressed pattern recognition

28 Baldini $M$, Lohman IC, Halonen M, et al. A polymorphism in the 5 ' flanking region of the CD14 gene is associated with circulating soluble CD14 levels and with total serum immunoglobulin E. Am f Respir Cell Mol Biol 1999;20:97683.

29 Wright AL, Holberg CJ, Halonen M, et al. Breastfeeding, maternal IgE and total serum IgE in childhood. F Allergy Clin Immunol 1999;104:589-94.

30 Martinez FD. Role of viral infections in the inception of asthma and allergies during childhood: could they be protective? Thorax 1994;49:1189-91.

31 Sepp E, Julge $\mathrm{K}$, Vasar $M$, et al. Intestinal microflora of Estonian and Swedish infants. Acta Paediatr 1997;86:95661

32 Bjorksten B, Naaber P, Sepp E, et al. The intestinal microflora in allergic Estonian and Swedish 2-year old children. Clin Exp Allergy 1999;29:342-6.

33 Matricardi PM, Rosmini F, Riondino S, et al. Exposures to foodborne and orofecal microbes versus airborne viruses in relation to atopy and allergic asthma: epidemiologic study. BMf 2000;320:412-7.

34 Yoshioka H, Iseki K, Fujita K. Development and differences of intestinal flora in the neonatal period in breast-fed and bottle-fed infants. Pediatrics 1983;72:317-21.

35 Wold AE, Adlerberth I. Does breastfeeding affect the infant's immune responsiveness? Acta Paediatr 1998;87:1922

36 Cunningham AS, Jelliffe DB, Jelliffe EFP. Breastfeeding and health in the 1980s: a global epidemiologic review. Pediatrics 1991;118:659-66.

37 Halonen M, Stern DA, Wright AL, et al. Alternaria as a major allergen for asthma in children raised in a desert environment. Am 7 Respir Crit Care Med 1997;155:135661.

38 American Academy of Pediatrics Work Group on Breastfeeding. Breastfeeding and the use of human milk. Pediatrics 1997;100:1035-9. 